See discussions, stats, and author profiles for this publication at: https://www.researchgate.net/publication/325813530

\title{
The Impact of a High-Fidelity Wave-to-Wire Model in Control Parameter Optimisation and Power Production Assessment
}

Conference Paper · June 2018

DOI: 10.1115/OMAE2018-77501

CITATIONS

3

2 authors:

2. Markel Penalba

1. Mondragon Unibertsitatea

33 PUBLICATIONS 489 CITATIONS

SEE PROFILE

Some of the authors of this publication are also working on these related projects:

Project Neural control of blood pressure using nonlinear feedback models View project

Project High Fidelity Numerical Modelling of Ocean Wave Energy Systems View project
READS

222

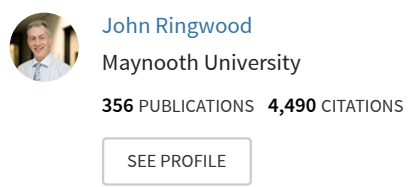




\author{
Proceedings of the ASME 2018 37th International Conference on Ocean, Offshore and Arctic Engineering \\ OMAE2018 \\ June 17-22, 2018, Madrid, Spain
}

\title{
OMAE2018-77501
}

\section{THE IMPACT OF A HIGH-FIDELITY WAVE-TO-WIRE MODEL IN CONTROL PARAMETER OPTIMISATION AND POWER PRODUCTION ASSESSMENT}

\author{
Markel Penalba \\ Centre for Ocean Energy Research \\ Electronic Engineering Department \\ Maynooth University \\ Maynooth, Co. Kildare, Ireland \\ Email: markel.penalbaretes.2015@mumail.ie
}

\author{
John V. Ringwood \\ Centre for Ocean Energy Research \\ Electronic Engineering Department \\ Maynooth University \\ Maynooth, Co. Kildare, Ireland \\ Email: john.ringwood@mu.ie
}

\begin{abstract}
Accurate control parameter optimisation and power production assessment is essential to evaluate the performance of a wave energy converter (WEC). However, commonly used numerical models excessively simplify the power take-off (PTO) system of the WEC, which may strongly affect power production predictions. Therefore, the present paper compares a commonly used WEC model that includes nonlinear viscous losses and an ideal PTO system model, referred to as NLideal, with a highfidelity wave-to-wire model (HFW2W) model. Results show the incapacity of the commonly used NLideal model to accurately optimise control parameters, particularly using reactive control. Likewise, the annual mean power production (AMPP) predicted using the NLideal model is significantly overestimated, with differences of up to $160 \%$ with respect to the more realistic HFW2W model. More dramatically, the use of control parameters optimised with the NLideal model in the HFW2W model results in negative AMPP, meaning that the WEC consumes more energy than it produces.
\end{abstract}

\section{INTRODUCTION}

Despite the great effort devoted to the development of creative technological solutions to absorb energy from ocean waves, none of the wave energy converters (WECs) suggested in the literature has yet shown economical viability. Precise mathematical models are essential in the development of the successful prototypes, to understand the behaviour of WECs through simulation, to design precise model-based control strategies that allow for energy maximization, and to accurately assess the power production capabilities of WECs.

The vast majority of the studies focus on accurately solving the wave-absorber hydrodynamic interaction, where absorber refers to the part of the WEC that absorbs energy from ocean waves, as illustrated in Figure 1. In fact, the power take-off (PTO) system is often either neglected or excessively simplified in these studies. However, the impact of PTO system dynamics and losses is demonstrated to be relevant for an accurate evaluation of WECs' holistic behaviour [1].

Therefore, precise mathematical models that incorporate all the necessary information of the different components from waves to the electricity grid, known as wave-to-wire (W2W) models, are essential to accurately study the performance of WECs. Figure 1 illustrates the path from ocean waves to the electricity grid using a hydraulic PTO system, where the different stages and control inputs for each stage $(\alpha, \beta$ and $\gamma)$ are defined.

Wave-to-wire models with different levels of detail have been suggested in the literature for different applications, such as WEC simulation [2-4], energy maximizing control design and evaluation [5-8], PTO design [9-11], or power quality analysis [12]. Nevertheless, it is essential to precisely represent the different components of the $\mathrm{W} 2 \mathrm{~W}$ model in order to obtain accurate results and draw meaningful conclusions.

The only studies in the literature that use W2W models for control parameter optimization, i.e. optimization of the PTO damping $\left(B_{P T O}\right)$ and stiffness $\left(K_{P T O}\right)$, and power production as- 


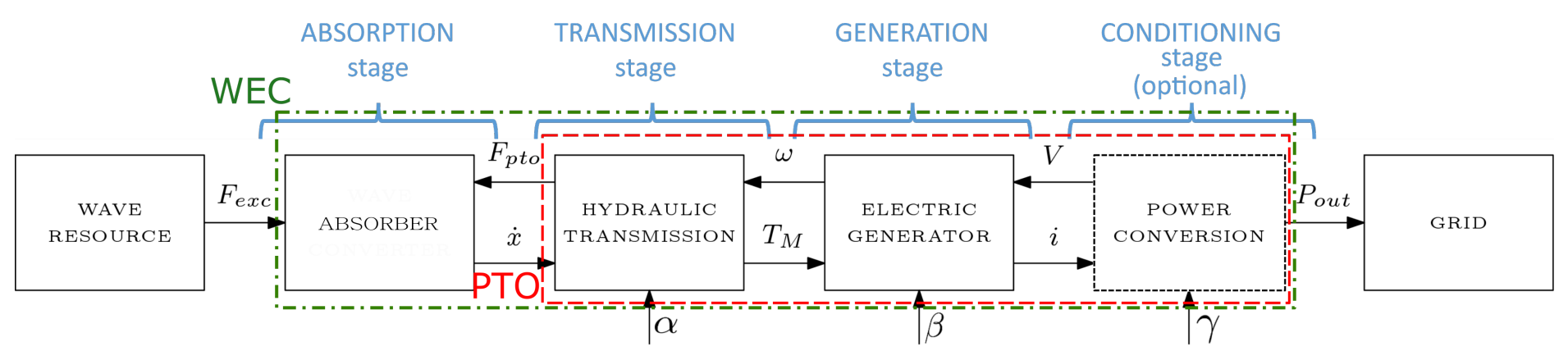

FIGURE 1: Different subsystems from ocean waves to the electricity grid for a WEC with a hydraulic transmission system.

sessment are [7] and [11], respectively. However, [7] optimises control parameters considering losses in the PTO system by means of a constant efficiency parameter, while, in the W2W model suggested in [11] for power production assessment, the electrical generator is added in the post-processing and is modelled using a constant efficiency as a function of the rated power, neglecting the effects of the rotational speed variations and inertia effects.

Therefore, the present paper focuses on the optimization of control parameters and power production assessment using a high-fidelity W2W model with a hydraulic PTO system that includes all the necessary information [1].

Accurate power production assessment is crucial for the development of WECs, since it allows for evaluation and comparison of different technologies in different geographical locations. Several studies in the literature analyse the power production assessment of different WECs, using either isolated devices $[11,13-18]$ or arrays $[19,20]$ in the analysis. Power production assessment is also an essential tool to evaluate the economical viability of WECs or wave energy arrays, for which effects of the PTO systems should not be neglected. Finally, power production assessment is also used to evaluate the impact of wave resource variations on WECs [21].

The predominant method for power production assessment consists of combining the scatter diagram of a specific location with the power output capabilities of a WEC for the different sea-states included in the scatter diagram, known as power matrix. The scatter diagram is generated from the historical data collected over a reasonable time period (generally over a year), and the power matrix of the WEC is calculated using numerical models. Other methods for power production assessment that avoid the use of power matrices are discussed in [18], where the potential inaccuracies of the power matrix approach are studied compared to the full spectrum representation. Furthermore, [18] also analyses the inaccuracies related to the WEC dynamical description.

The power matrix representation is used in the present paper due to its simplicity and its appealing computational properties, compared to the complexity of the $\mathrm{W} 2 \mathrm{~W}$ model employed in this paper. Indeed, the objective of this paper is to analyse the inaccu- racies related to the WEC dynamical description, highlighting the impact of high-fidelity $\mathrm{W} 2 \mathrm{~W}$ models compared to the more common hydrodynamic models with excessively simplified PTO system model.

The remainder of the paper is as follows: Section 2 describes the two mathematical models used in this paper, i.e. the nonlinear hydrodynamic model with an ideal PTO model and the high-fidelity W2W model, Section 3 presents the selected location, and the characteristics of the WEC, the PTO system and control strategies, Section 4 shows the results of control parameter optimization and power production assessment using the two mathematical models, comparing results and highlighting the differences, and Section 5 draws the conclusions of the study.

\section{MATHEMATICAL MODELS}

Time-domain numerical models are the standard methods to obtain the WEC output and generate the power matrices in power production assessment studies [22]. Two significantly different time-domain models are used in the present paper.

The first mathematical model, henceforth referred to as nonlinear ideal (NLideal) model, describes the wave-absorber interaction using linear hydrodynamics with nonlinear viscous effects and represents the PTO system as an ideal spring-damper system, similarly to [13]. Conversely, the second mathematical model, referred to as the high-fidelity wave-to-wire $(H F W 2 W)$ model in the following, includes nonlinear viscous effects and nonlinear Froude-Krylov (FK) forces in the hydrodynamic model and all the important nonlinear effects and losses of the PTO system.

\subsection{Nonlinear-ideal model}

The dynamical equation of the NLideal model is based on the Cummins equation as follows [23]:

$$
\begin{aligned}
\left(\mathbf{M}+\mu_{\infty}\right) \ddot{x}=F_{e x}-\mathbf{K}_{\mathbf{H}} x-\int_{0}^{t} & K_{\text {rad }}(t-\tau) \dot{x}(\tau) d t \\
& +F_{\text {visc }}+F_{P T O}+F_{\text {EndStop }}
\end{aligned}
$$

where $\mathbf{M}$ and $\mu_{\infty}$ are the mass and infinite added-mass matri- 
ces of the device, $x(t), \dot{x}(t)$ and $\ddot{x}(t)$ are the displacement, velocity and acceleration vectors of the device for the corresponding degrees of freedom (DoFs), respectively, $F_{\text {ex }}(t)$ is the excitation force vector (including diffraction and FK forces), $\mathbf{K}_{\mathbf{H}}$ the hydrostatic stiffness matrix, $K_{\text {rad }}$ the radiation impulse response vector, $t$ the time interval in which the dynamics of the WEC are studied, $\tau$ the length of $K_{\text {rad }}, F_{\text {visc }}$ the viscous force vector, $F_{P T O}$ the PTO force vector, and $F_{E n d S t o p}$ the force that reproduces the end-stop effect of the PTO system. Aspects like drift forces or forces induced by ocean currents and wind are neglected in the present study.

The wave-absorber interaction is modelled via linear potential theory, which assumes an inviscid and incompressible fluid, irrotational flow and small motion amplitudes of the WEC. Frequency-domain (FD) hydrodynamic coefficients are obtained with the boundary element method code NEMOH [24]. Hence, using the excitation force FD coefficient $\left(F_{e x}(f)\right)$ and a spectral density function $(S(f))$ based on the JONSWAP spectrum [25], the wave excitation force signal can be obtained for each seastate as follows:

$$
F_{e x}(t)=\sum_{k=1}^{N} A_{k} F_{e x}\left(f_{k}\right) \cos \left(2 \pi f_{k} t+\phi_{k}\right)
$$

where $N$ is the number of analysed frequencies, $A_{k}=$ $\sqrt{2 S\left(f_{k}\right) \Delta f}, f_{k}$ is the frequency, $\Delta f$ the frequency step and $\phi_{k}$ a set of random phases.

Viscous force Fully linear models are shown to overestimate the motions of the devices and, as a consequence, the power absorption [26]. Hence, a simple and common way to avoid this overestimation is to include viscous effects using a quadratic term, known as the drag coefficient $\left(C_{D}\right)$, via Morison's equation [27]:

$$
F_{v i s c}=\frac{1}{2} \rho C_{D} A_{D}\left(\dot{x}-V_{0}\right)\left|\dot{x}-V_{0}\right|
$$

where $\rho$ is the water density, $A_{D}$ the characteristic area of the WEC and $V_{0}$ the velocity of the undisturbed flow.

Apart from the viscous effect, no other hydrodynamic nonlinear effect is included in the NLideal model. Similar models have been widely used in the literature for power production assessment [13,21].

Power take-off force The PTO system is excessively simplified in the NLideal model, as in the vast majority of the studies in the literature, using an ideal spring-damper system,

$$
F_{P T O}=-K_{P T O} x-B_{P T O} \dot{x}
$$

The damping term $\left(B_{P T O}\right)$ is the dissipative term that absorbs energy from ocean waves, while the stiffness $\left(K_{P T O}\right)$ is required to increase the absorbed power. The damping term is always positive, while the stiffness can be positive, zero or negative. In the case of $K_{P T O}=0$, the control strategy is known as resistive control, and reactive control for $K_{P T O} \neq 0$.

Constraints Wave energy converters are, in general, designed to operate over a specific range of conditions and, as a consequence, the PTO system is designed to operate within these conditions. Therefore, the PTO system may have limitations when extracting energy from ocean waves. The main PTO limitations include maximum displacement (end stop), maximum velocity and maximum applicable force $\left(F_{P T O}^{M A X}\right)$.

These three constraints are included in the mathematical models of the present study. Only the displacement limitation requires a new force $\left(F_{\text {EndStop }}\right)$ in Equation (1) to implement such a constraint, which can be modelled as a spring and/or damping that activates as soon as the motion amplitude reaches a threshold value close to the end stop, applying a force opposite to the motion. A simple linear end-stop damping $\left(B_{E n d S t o p}\right)$ has been implemented in this study.

\subsection{High-fidelity wave-to-wire model}

The $H F W 2 W$ model incorporates nonlinear FK forces $\left(F_{F K}\right)$ in the wave-absorber hydrodynamic interaction, following the recommendations given in [28]. Hence, Equation (1) is modified as follows:

$$
\begin{aligned}
\left(\mathbf{M}+\mu_{\infty}\right) \ddot{x}=F_{F K}-F_{\text {diff }}-\int_{0}^{t} & K_{\text {rad }}(t-\tau) \dot{x}(\tau) d t \\
& +F_{\text {visc }}+F_{\text {pis }}+F_{\text {EndStop }}
\end{aligned}
$$

where $F_{F K}$ is solved algebraically calculating the pressure field over the instantaneous wetted surface using the computationally efficient method described in [29] for axisymmetric heaving point absorbers, $F_{\text {diff }}$ is the diffraction force, and $F_{\text {pis }}$ the hydraulic piston force. The importance of including nonlinear FK forces is demonstrated in [26,30], particularly under aggressive energy maximising control strategies, such as latching [26] or reactive control [30].

Power take-off model However, the main difference between the HFW2W model and the NLideal model is the PTO system model, which includes all the important dynamics and losses of a hydraulic transmission system coupled to an electric generator. In addition, this PTO model is validated against experimental results using hydraulic system and electric generator test rigs in [1,31] and [32], respectively.

The hydraulic PTO system implemented in the $H F W 2 W$ model includes a hydraulic cylinder, a low-pressure accumulator, relief-valves and a variable-displacement hydraulic motor. The mathematical model for the cylinder includes end-stop constraints, friction losses, and compressibility and inertia effects, providing the final piston force $\left(F_{p i s}\right)$ as follows,
Copyright (C) 2018 by ASME 


$$
F_{p i s}=A_{p} \Delta p+F_{f r i c}+F_{i n}
$$

where $A_{p}$ is the piston area, $\Delta p$ the pressure different between the cylinder chambers, $F_{\text {fric }}$ the friction force modelled following the Stribeck formula [33] and $F_{\text {in }}$ the inertia force.

Pressure dynamics in cylinder chambers, including compressibility effects, are given as,

$$
\dot{p}=\frac{\beta_{e f f}}{V+A_{p} x_{p}}\left(Q-\dot{x}_{p} A_{p}\right)
$$

where $\beta_{\text {eff }}$ is the effective bulk modulus, $V$ the minimum volume in the cylinder chamber, $x_{p}$ and $\dot{x}_{p}$ are the piston position and velocity, and $Q$ is the flow entering or exiting the cylinder chamber.

Relief valves are passive check-valves that open only if pressure in the hoses exceeds the maximum pressure allowed in the system and are modelled using the orifice equation [33], as shown in Equation (8). The low-pressure accumulator is essential to avoid pressure drops in the low-pressure line that can lead to undesirable phenomena like cavitation. Pressure $\left(p_{a c c}\right)$ and volume variations in the accumulator are described via an isentropic and adiabatic process, as described in Equation (9).

$$
\begin{gathered}
Q_{v}=C_{d} A_{v}(\Delta p) \operatorname{sign}(\Delta p) \sqrt{\frac{2}{\rho_{\text {oil }}}|\Delta p|} \\
p_{\text {acc }}=p_{\text {pre }}\left(\frac{V_{\text {tot }}}{V_{\text {gas }}}\right)^{\gamma}
\end{gathered}
$$

where $Q_{v}$ is the flow through the valve, $C_{d}$ the discharge coefficient, $A_{v}$ the valve opening area, $\rho_{\text {oil }}$ the density of the hydraulic oil, $V_{t o t}$ the total volume of the accumulator, $V_{g a s}$ the gas volume in the accumulator, $p_{\text {pre }}$ the pre-charged pressure of the accumulator, and $\gamma$ the adiabatic index for an ideal gas.

Hydraulic motors convert hydraulic pressure and flow into mechanical torque and rotational speed of the motor shaft coupled to an electric generator. The model of the hydraulic motor includes losses due to friction and leakages via the Schlösser loss model $[34,35]$. The output flow $\left(Q_{M}\right)$ and torque of the motor $\left(T_{M}\right)$ can be described as follows,

$$
\begin{aligned}
Q_{M} & =\alpha D_{\omega} \omega_{M}-Q_{\text {losses }}, \\
T_{M} & =\alpha D_{\omega} \Delta p_{M}-T_{\text {losses }}
\end{aligned}
$$

where $\alpha$ is the motor displacement fraction, $D_{\omega}$ the displacement of the hydraulic motor, $\omega_{M}$ the rotational speed of the shaft, $\Delta p_{M}$ the pressure difference across the hydraulic motor, and $Q_{\text {losses }}$ and $T_{\text {losses }}$ represent volumetric and mechanical losses in the hydraulic motor. Further details of the hydraulic transmission model, such as the identification of the parameters of the Stribeck friction model or Schösser loss model, are provided in [31].

Finally, with respect to the electric generator, the model of a squirrel cage induction generator is implemented, following the equivalent two-phase $(d q)$ equations presented in [36],

$$
\begin{array}{r}
V_{s d}=R_{s} i_{s d}-\omega \lambda_{s q}+L_{s} \frac{d}{d t} i_{s d}+L_{m} \frac{d}{d t}\left(i_{s d}+i_{r d}\right), \\
V_{s q}=R_{s} i_{s q}+\omega \lambda_{s d}+L_{s} \frac{d}{d t} i_{s q}+L_{m} \frac{d}{d t}\left(i_{s q}+i_{r q}\right), \\
0=R_{r} i_{r d}-\left(\omega-\omega_{r}\right) \lambda_{r q}+L_{r} \frac{d}{d t} i_{r d}+L_{m} \frac{d}{d t}\left(i_{s d}+i_{r d}\right), \\
0=R_{r} i_{r q}+\left(\omega-\omega_{r}\right) \lambda_{r d}+L_{r} \frac{d}{d t} i_{r q}+L_{m} \frac{d}{d t}\left(i_{s q}+i_{r q}\right)
\end{array}
$$

where $V$ is the voltage, $i$ the current, $R$ the resistance and $\lambda$ the flux. Subscripts $s$ and $r$ are used for the stator and rotor, while $d$ and $q$ refer to the direct and quadrature axes, respectively. $\omega$ and $\omega_{r}$ are the angular speed of the reference frame and the rotor, respectively.

The electromagnetic torque $\left(T_{e}\right)$, rotational speed of the generator shaft and the generated electric power $\left(P_{e}\right)$ are given by Equation (12),

$$
\begin{array}{r}
T_{e}=\frac{3 N_{p}}{4}\left(\lambda_{s d} i_{s q}-\lambda_{q s} i_{d s}\right), \\
\dot{\omega}_{r}=\frac{N_{p}}{2 J_{\text {shaft }}}\left(T_{e}-T_{M}-B_{\text {wind }} \omega_{r}\right), \\
P_{e}=\frac{3}{2}\left(V_{s d} i_{s d}+V_{s q} i_{s q}\right)
\end{array}
$$

where $N_{p}$ is the number of poles in the generator, $J_{\text {shaft }}$ the shaft moment of inertia and $B_{\text {wind }}$ the friction/windage damping.

\section{CASE STUDY}

To carry out the comparison between the two mathematical models described in Section 2, a specific case study needs to be defined, including the location and its wave energy potential, the absorber, and PTO and control characteristics. Table 1 summarises all the relevant information of the case study.

\subsection{Absorber}

The selected WEC is a floating spherical buoy with 5-m diameter inspired by the Wavestar device. However, for the sake of simplicity, the spherical buoy is restricted to heave motion only, as illustrate din Figure 2. In addition, the spherical device is especially interesting due to its non-uniform cross-sectional area that leads to nonlinear FK effects [26]. Table 1 provides all the necessary information about the absorber. 


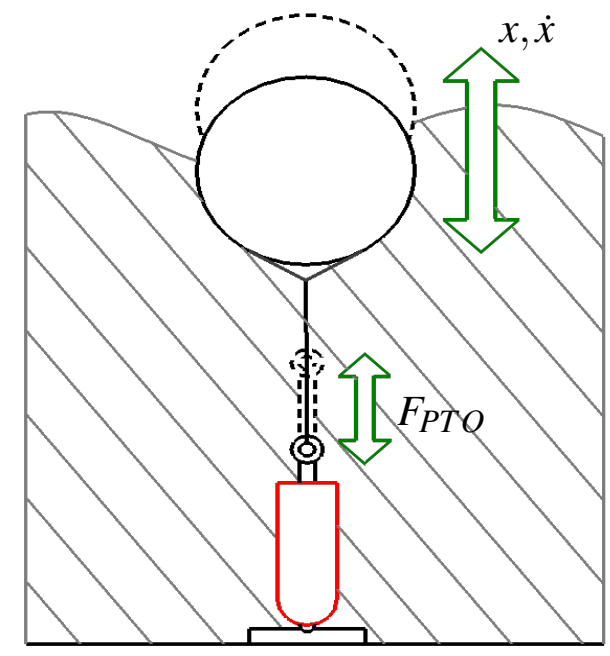

FIGURE 2: Diagram of the heaving point absorber WEC.

\subsection{Location}

The WEC is analysed in a single location, since this paper focuses on the inaccuracies related to the WEC dynamical description. The selected location is Belmullet, off the west coast in Ireland, for which the Irish Marine Institute [37] provided the data. Belmullet has a high wave energy potential (one of the locations with the highest potential in Europe [20]). The scatter diagram for the location in Belmullet is shown in Figure 3 and the main characteristics of the location, such as the peak period and significant wave height with the highest frequency of occurrence ( $T_{p}^{\prime}$ and $H_{s}^{\prime}$, respectively) and the mean annual incoming wave energy per meter of wave front $(J)$ are presented in Table 1. Finally, it should be noted that the operational space of the WEC is limited to $H_{s} \leq 5 m$, as illustrated by the red line in Figure 3 .

In addition, the Belmullet location is particularly appropriate for this study, since the real spectra are similar to the standard spectral shapes, e.g. JONSWAP, which reduces the inaccuracies due to the misrepresentation of the resource by the power matrix approach [18].

\subsection{Power take-off design and control strategies}

The design of the PTO system is characterised by the pressure and flow requirements of the hydraulic system to absorb energy from ocean waves. The main parameters to be defined in a hydraulic PTO system are the $A_{p}$ and $D_{\omega}$, which are defined following three main constraints of WECs with hydraulic transmission systems: maximum pressure-difference in the cylinder chambers, and maximum WEC displacement and velocity.

Pressure should be as high as possible to minimize losses. However, the efficiency of a hydraulic motor, according to the efficiency map shown in [31], reduces with pressures above 300

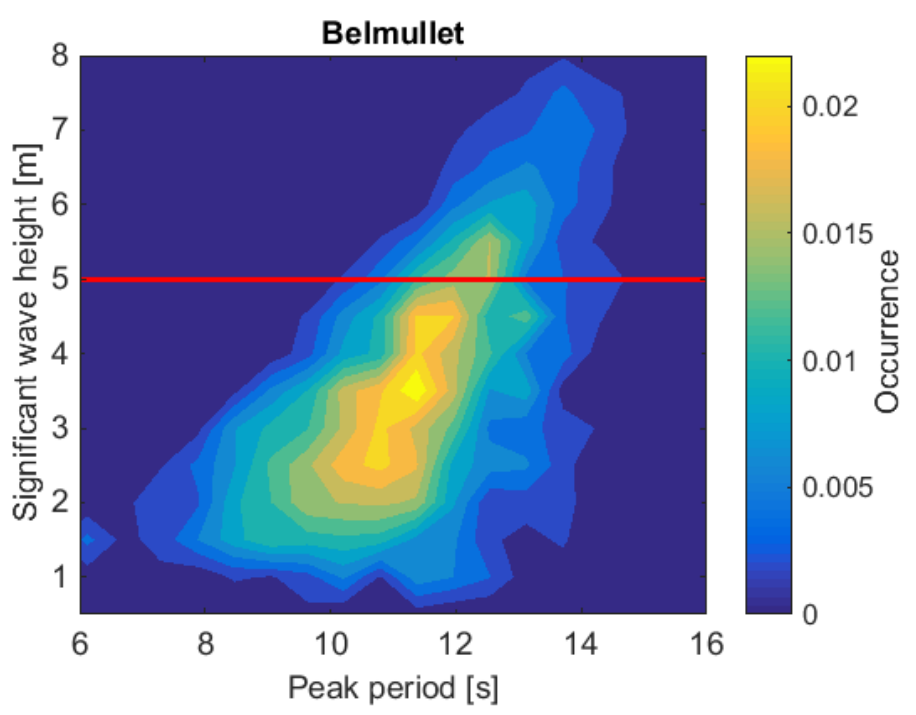

FIGURE 3: Scatter diagram of the Belmullet test site, where the red line shows the limit of the operational space.

bar, so the maximum pressure difference allowed in the system can be set as 300 bar. Hence, the design of the hydraulic cylinder piston area is defined so that the maximum force is provided when the pressure difference between the two cylinder chambers is 300 bar. The maximum required force for the spherical WEC is $420 \mathrm{kN}$, based on the Wavestar device requirements [7], which results in a piston area of $140 \mathrm{~cm}^{2}$.

WEC displacement and velocity constraints substantially influence the power absorption of the WEC $[38,39]$ and, thus, constraints should be carefully chosen. However, the optimization of the PTO is beyond the scope of the present study. Two typical values are considered for WEC displacement and velocity constraints: $2 \mathrm{~m}$ and $2 \mathrm{~m} / \mathrm{s}$, respectively. The velocity constraint provides the maximum possible flow that can be used to determine the required motor displacement. Assuming the PTO operates at a fixed-speed $1500 \mathrm{rpm}$, a hydraulic motor of $1120 \mathrm{cc}$ is required.

The selection of the electric generator is particularly complex due to the highly irregular output power signal of WECs. The rated power of the generator needs to be large enough to follow the highest absorbed power peaks, while keeping a reasonable efficiency in low energetic sea-states. In this case, a generator of $74.5 \mathrm{~kW}$ has been selected, using the parameters of the electric generator provided in [40]. Table 1 presents the main characteristics of the PTO system implemented in the present paper.

It should be noted that the PTO components' dimensions are not necessarily optimal and, therefore, results obtained with the $H F W 2 W$ model could probably be improved by accurately selecting PTO component dimensions.

In addition to the PTO system characteristics, the selection of an appropriate control strategy is crucial. In order to evaluate the impact of the $H F W 2 W$ model under different control conditions, both resistive and reactive control are analysed. In the 
TABLE 1: Main characteristics of the selected location, the absorber and the PTO system.

\begin{tabular}{|c|c|c|}
\hline \multirow{3}{*}{ 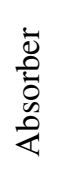 } & WEC diameter & $5 \mathrm{~m}$ \\
\hline & Mass & $33.3 \mathrm{~T}$ \\
\hline & Natural period & $3.17 \mathrm{~s}$ \\
\hline \multirow{3}{*}{ 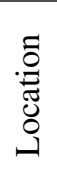 } & $T_{p}^{\prime}$ & $11.3 \mathrm{~s}$ \\
\hline & $H_{s}^{\prime}$ & $3.5 \mathrm{~m}$ \\
\hline & $J$ & $78 \mathrm{~kW} / \mathrm{m}$ \\
\hline \multirow{5}{*}{$\stackrel{0}{\circ}$} & $A_{p}$ & $140 \mathrm{~cm}^{2}$ \\
\hline & Cylinder length & $2 \mathrm{~m}$ \\
\hline & $D_{\omega}$ & $1120 \mathrm{cc}$ \\
\hline & $P_{e}^{\text {rated }}$ & $74.5 \mathrm{~kW}$ \\
\hline & $J_{\text {shaft }}$ & $4.45 \mathrm{~kg} \cdot \mathrm{m}^{2}$ \\
\hline
\end{tabular}

case of the NLideal model, $F_{P T O}$, defined as in Equation (4), directly acts in the wave-absorber hydrodynamic interaction as an external force, as shown in Equation (1).

Conversely, in the case of the $H F W 2 W$ model, $F_{P T O}$ is used to determine the control input to the hydraulic cylinder ( $\alpha$ in Figure 1), controlling the pressure difference between the cylinder chambers. Hence, the PTO force that acts in the wave-absorber hydrodynamic interaction is $F_{p i s}$, which includes other effects, such as friction or inertia, as shown in Equation (5).

The $B_{P T O}$ and $K_{P T O}$ parameters are optimised for each seastate to maximize the energy absorption. The optimisation is carried out via the exhaustive search algorithm, ensuring that the optimal value is always the global maximum.

\section{RESULTS}

Results are divided into two parts, where optimal control parameters obtained from the NLideal and $H F W 2 W$ models are compared in the first part, and annual mean power production (AMPP) predictions using the NLideal and HFW2W models are studied in the second. In both parts, the comparison is carried out using resistive and reactive control strategies.

Differences between the output from the $H F W 2 W$ and the NLideal models are calculated in percentage terms as follows,

$$
\Delta[\%]=\frac{y_{H F W 2 W}-y_{N \text { Lideal }}}{y_{H F W 2 W}} \times 100
$$

where $y_{H F W 2 W}$ and $y_{N L i d e a l}$ are the outputs from the $H F W 2 W$ and NLideal models, respectively. Note that $\Delta$ can take positive or negative values, negative values meaning that outputs from the NLideal model are overestimated, compared to the $H F W 2 W$ model.

\subsection{Control parameter optimisation}

Accurately calculating control parameters is crucial to maximize energy generation from ocean waves, and, as a consequence, accurately predict the AMPP of a WEC in a specific location.

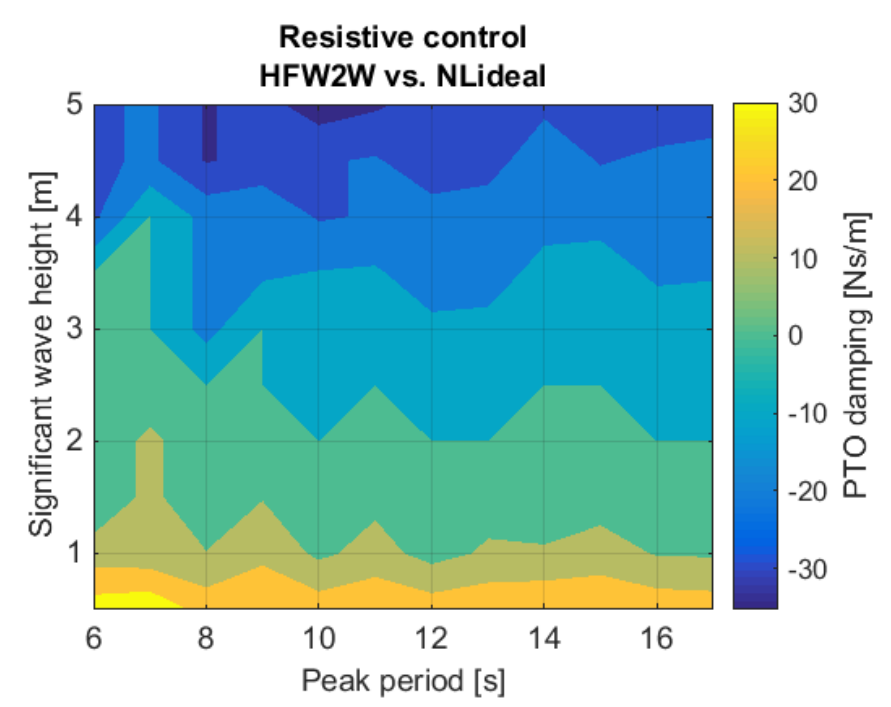

FIGURE 4: Resistive control parameter differences between the $H F W 2 W$ and NLideal models $\left(\triangle B_{P T O}\right)$ over the whole operational space.

In the case of resistive control, differences between the control parameters (only $B_{P T O}$ ) optimised using the $H F W 2 W$ model and the NLideal model are relatively important. Figure 4 illustrates these differences over the whole operational space, where the NLideal model appears to overestimate control parameters for more energetic sea-states $\left(H_{s} \geq 3 m\right)$, while underestimate for less energetic sea-states $\left(H_{s} \leq 3 m\right)$. One can observe in Figure 4 that $\Delta B_{P T O}$ values are relatively low $(-10 \% \leq \Delta \leq 10 \%)$ for medium sea-states $\left(1.5 \leq H_{s} \leq 3.5\right)$, which suggests that the impact of inaccurate control parameters in that area may be lower.

Table 2 presents the optimal control parameters, generated average power values using optimal control parameters $\left(P_{g e n}^{o p t}\right)$ and generated average power using control parameters optimized with the NLideal model $\left(P_{\text {gen }}^{\text {NLideal }}\right)$ for resistive and reactive control at the sea-state with the highest occurrence in Belmullet $\left(T_{p}=11.3 s \& H s=3.5 m\right)$. For resistive control, the NLideal model is shown to overestimate the optimal control parameter by almost $9 \%$ and the generated power by over $30 \%$. However, if the $B_{P T O}$ optimised with the NLideal model is used in the HFW2W 
TABLE 2: Optimal control parameters and corresponding generated power for the $11.3 \mathrm{~s}$ peak period and $3.5 \mathrm{~m}$ significant wave height sea-state, using resistive and reactive control.

\begin{tabular}{|c|c|c|c|c|c|}
\hline & & & NLideal & $H F W 2 W$ & $\Delta[\%]$ \\
\hline \multirow{3}{*}{ 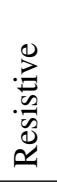 } & \multirow{3}{*}{ 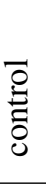 } & $B_{P T O}[\mathrm{kNs} / \mathrm{m}]$ & 250 & 230 & -8.7 \\
\hline & & $P_{\text {gen }}^{o p t}[\mathrm{~kW}]$ & 39.23 & 29.70 & -32.1 \\
\hline & & $P_{\text {gen }}^{N \text { Lideal }}[\mathrm{kW}]$ & N/A ${ }^{1}$ & 29.24 & -1.5 \\
\hline \multirow{4}{*}{ 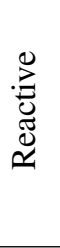 } & \multirow{4}{*}{ 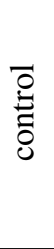 } & $B_{P T O}[\mathrm{kNs} / \mathrm{m}]$ & 90 & 130 & 30.8 \\
\hline & & $K_{P T O}[\mathrm{kN} / \mathrm{m}]$ & -175 & -100 & 75 \\
\hline & & $P_{g e n}^{o p t}[\mathrm{~kW}]$ & 123.7 & 53.6 & -130.8 \\
\hline & & $P_{\text {gen }}^{\text {NLideal }}[\mathrm{kW}]$ & N/A & $U n R^{2}$ & $U n R$ \\
\hline
\end{tabular}

${ }^{1}$ The abbreviation N/A is used for not applicable.

${ }^{2}$ The abbreviation $U n R$ is used for unrealistic.

model, generated power difference is low (about 1.5\%), meaning that the impact of the control parameter overestimation of the NLideal model is relatively weak. This difference is calculated by comparing $P_{\text {gen }}^{\text {NLideal }}$ and $P_{\text {gen }}^{\text {opt }}$ for the $H F W 2 W$ model, based on Equation (13) as follows,

$$
\Delta[\%]=\frac{P_{\text {gen }}^{\text {NLideal }}-P_{\text {gen }}^{\text {opt }}}{P_{\text {gen }}^{\text {NLideal }}} \times 100
$$

Conversely, differences are significantly larger under reactive control, as illustrated in Figure 5, where both control parameters and generated power, are significantly misestimated. Furthermore, this misestimation has an even more dramatic impact on power generation, because control parameters optimised with the NLideal model lead to unrealistic situations, as illustrated in Table 2 by the abbreviation $U n R$, where the WEC gets stuck at one of the cylinder end-stops for the whole simulation due to effect of the erroneously designed controller.

\subsection{Power production assessment}

Considering the whole operational space of the WEC, the AMPP can be calculated. Figure 6 (a) and (b) illustrate the generated power matrices under reactive control for the NLideal and $H F W 2 W$ models, respectively.

The main difference between the two power matrices in Figure 6 is the magnitude of the generated power, up to $200 \mathrm{~kW}$ in the case of the NLideal model and up to $80 \mathrm{~kW}$ for the $H F W 2 W$ model. This difference (a factor of 2.5) appears due to the PTO efficiency that is considered only in the $H F W 2 W$ model. To highlight differences between the two mathematical models, PTO and

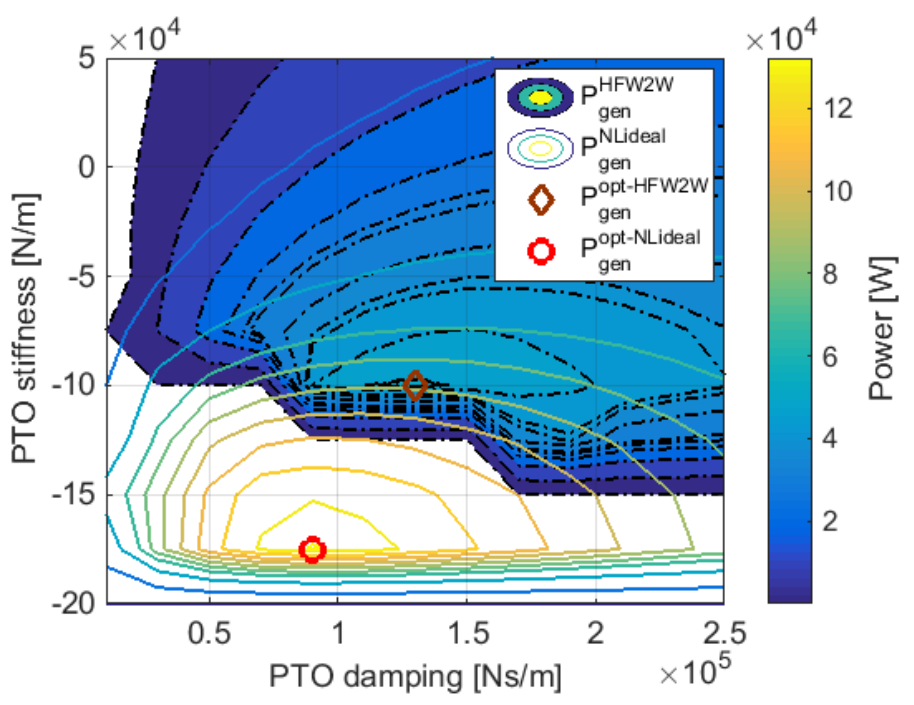

FIGURE 5: Reactive control parameter optimisation for the 11.3s peak period and $3.5 \mathrm{~m}$ significant height sea-state, using $H F W 2 W$ and NLideal models. (Readers are referred to the electronic version of the paper for the interpretation of the colour references in this figure.)

W2W efficiencies are calculated with the AMPP values from each model,

$$
\begin{aligned}
& \eta_{P T O}=\frac{A M P P_{\text {gen }}}{A M P P_{\text {abs }}} \times 100, \\
& \eta_{W 2 W}=\frac{A M P P_{\text {gen }}}{P_{\text {wave }}} \times 100=\frac{A M P P_{\text {gen }}}{J * L_{\text {charac }}} \times 100
\end{aligned}
$$

where $A M P P_{a b s}$ and $A M P P_{g e n}$ are the absorbed and generated AMPP, respectively, $P_{\text {wave }}$ is the theoretically extractable power with the WEC, and $L_{\text {charac }}$ is the characteristic length of the absorber, its diameter in this case.

In addition, one can observe that all the generated power values in Figure 6 (a) are positive, while negative generated power values appear at less energetic sea-states in Figure 6 (b). These negative power values appear due to the PTO dynamics and losses considered in the $H F W 2 W$ model, in particular, due to inertia effects of the electric generator. These negative values appear both, under resistive and reactive control, but always at less energetic sea-states, because the power of ocean waves is too low at these sea-states to counteract the high inertia of an electric generator of around $100 \mathrm{~kW}$. However, such a large generator is required to harvest energy from the power peaks at more energetic sea-states. An accurately designed PTO system may improve the power generation of the WEC, but PTO system optimisation is out of the scope of this paper. 


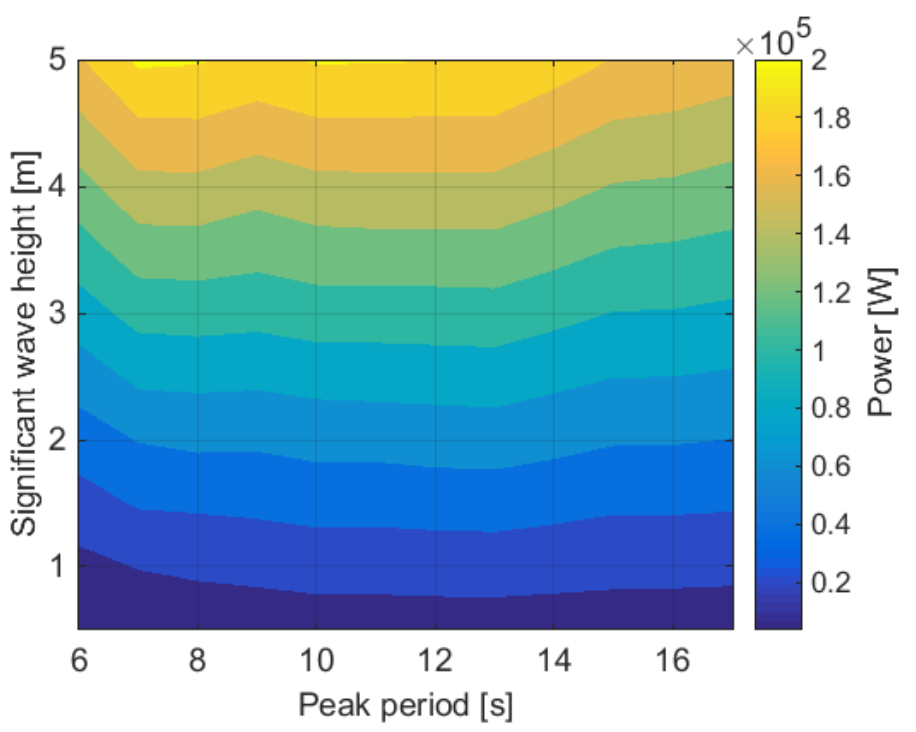

(a) Power matrix obtained with the NLideal model.

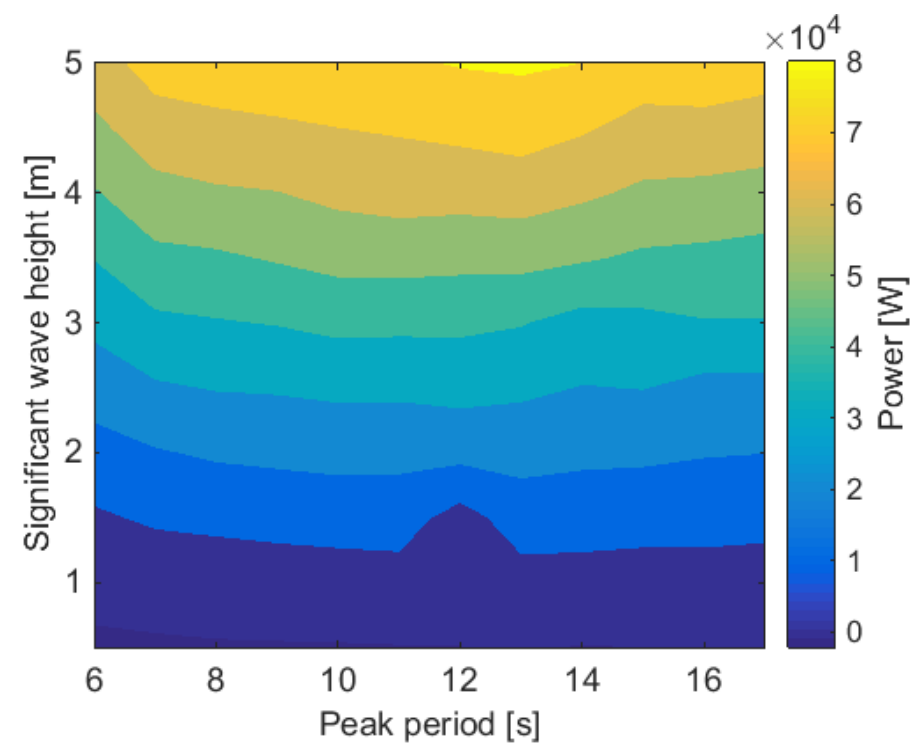

(b) Power matrix obtained with the $H F W 2 W$ model.

FIGURE 6: Power matrices obtained using the NLideal and $H F W 2 W$ models under reactive control.

The PTO efficiency and inertia effects play a significant role on the final power production, and, as a consequence, on the power production assessment. Table 3 presents the generated AMPP and efficiency values of the selected WEC at Belmullet, where the generated power overestimation of the NLideal model presented in Table 2 appears again: about $40 \%$ under resistive control and $160 \%$ under reactive control. Table 3 demonstrates the importance of using the $\eta_{W 2 W}$, rather than the $\eta_{P T O}$, to evaluate the holistic performance of WECs.
TABLE 3: Power production assessment of the spherical WEC under resistive and reactive control, including optimal AMPP values, and PTO and $\mathrm{W} 2 \mathrm{~W}$ efficiencies obtained using the NLideal and $H F W 2 W$ models; and AMPP values with misestimated control parameters.

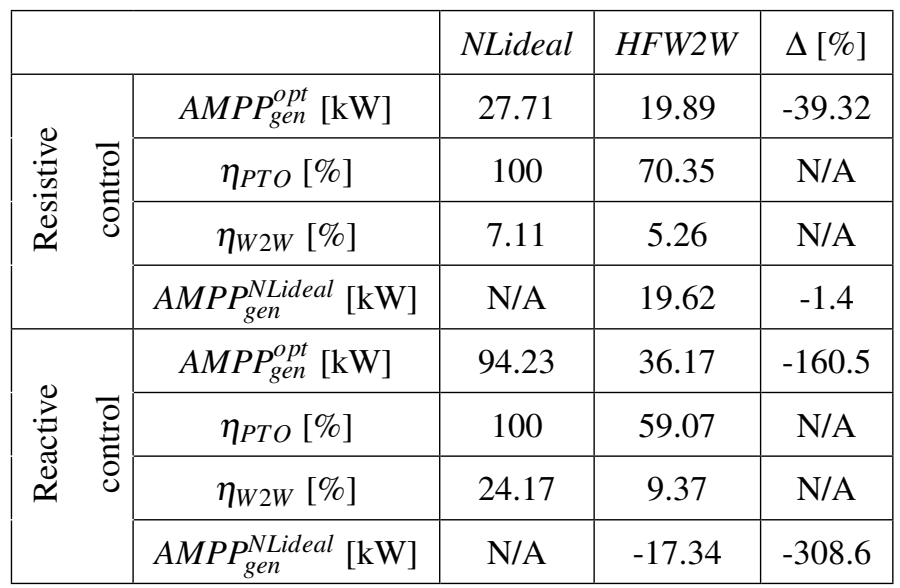

Finally, Table 3 also shows the impact of the misestimation of the control parameters using the NLideal model. Under resistive control, since the area with low $\triangle B_{P T O}$ values in Figure 4 includes the sea-states with the highest frequency occurrence (see Figure 3), the impact on $A M P P_{\text {gen }}$ is weak (about $1.5 \%$ of difference, calculated following Equation (14)). In contrast, the impact of that misestimation is dramatic under reactive control.

Figure 7 illustrates the power matrix obtained using the $H F W 2 W$ model with the control parameters optimised with the NLideal model. The blank spaces correspond to the unrealistic situations due to the erroneously designed controller, in which the WEC is considered to be non-operational. Comparing Figure 7 with Figure 6 (b), one can note that positive values are significantly lower (up to a factor 3) while negative values are even more negative (up to a factor 2), which dramatically results in negative $A M P P_{\text {gen }}$, as shown in Table 3.

Despite the obvious benefits of the $H F W 2 W$ model over the NLideal model, it should be noted that computational requirements of the $H F W 2 W$ model are prohibitive for any kind of optimisation and power production assessment purpose (over 100 times slower than the NLideal model, mainly due to the extremely small time-steps required to capture the very fast electrical dynamics of the electric generator).

\section{CONCLUSION}

The present paper compares a commonly used numerical model with an ideal power take-off system (NLideal) to a comprehensive wave-to-wire model $(H F W 2 W)$, for the optimisation of control parameters and power production assessment.

The need of a wave-to-wire model that incorporates the necessary information from waves to the electricity grid to accu- 


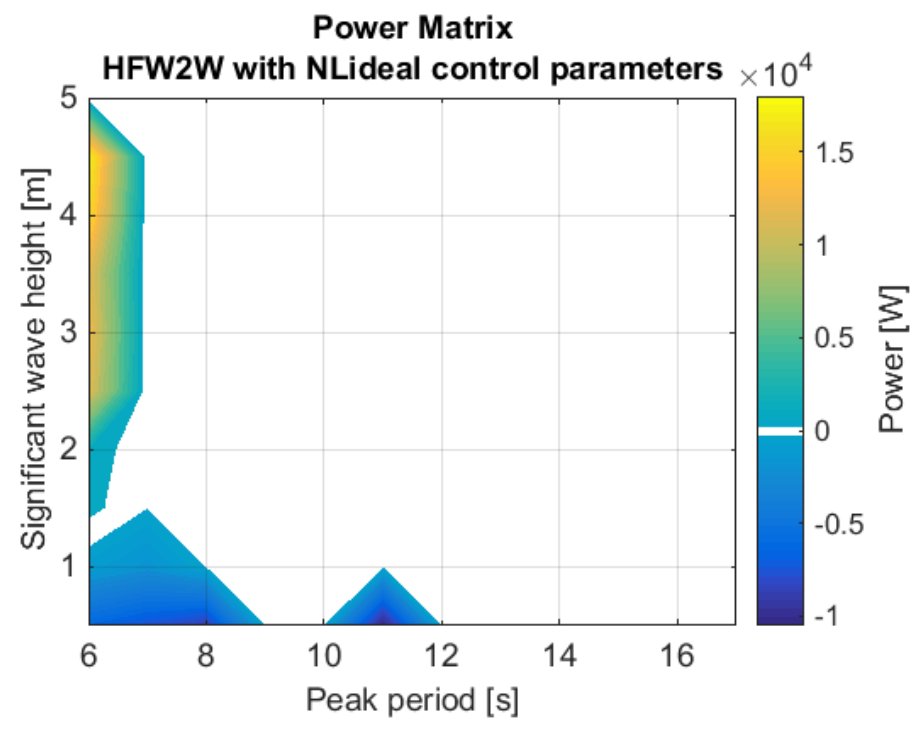

FIGURE 7: Power matrix obtained using the $H F W 2 W$ model and misestimated control parameters optimized with the NLideal model, where blank spaces illustrate unrealistic situations due to erroneously designed controller.

rately predict power production of the WECs is demonstrated, showing that extremely simplifying wave-absorber hydrodynamic interactions, and power take-off dynamics and losses may incur power overestimations of up to $160 \%$. In addition, the impact of optimising control parameters with the NLideal model is shown, which can be dramatic under reactive control, resulting in negative annual mean power production values.

However, it should be noted that the $H F W 2 W$ model presented in this paper is not appropriate for optimization or power assessment purposes, due to its prohibitive computational requirements. Therefore, a reduced or simplified version of the $H F W 2 W$ with significantly lower computational requirements is crucial to precisely design controllers or assess power generation capabilities of wave energy converters.

\section{ACKNOWLEDGMENT}

This material is based upon works supported by the Science Foundation Ireland under Grant No. 13/IA/1886.

\section{REFERENCES}

[1] Penalba, M., and Ringwood, J. "A complete validated wave-to-wire multi-rate computational model for wave energy converters". Submitted to Renewable Energy.

[2] Josset, C., Babarit, A., and Clément, A. H., 2007. "A waveto-wire model of the searev wave energy converter". Proceedings of the Institution of Mechanical Engineers, Part
M: Journal of Engineering for the Maritime Environment, 221(2), pp. 81-93.

[3] Lawson, M., Yu, Y.-H., Nelessen, A., Ruehl, K., and Michelen, C., 2014. "Implementing nonlinear buoyancy and excitation forces in the wec-sim wave energy converter modeling tool". In ASME 2014 33rd International Conference on Ocean, Offshore and Arctic Engineering, San Francisco, USA, Vol. 9B: Ocean Renewable Energy.

[4] So, R., Simmons, A., Brekken, T., Ruehl, K., and Michelen, C., 2015. "Development of pto-sim: A power performance module for the open-source wave energy converter code wec-sim". In ASME 2015 34th International Conference on Ocean, Offshore and Arctic Engineering, American Society of Mechanical Engineers, pp. V009T09A032V009T09A032.

[5] Ricci, P., Lopez, J., Santos, M., Ruiz-Minguela, P., Villate, J. L., Salcedo, F., and Falcão, A. F. O., 2011. "Control strategies for a wave energy converter connected to a hydraulic power take-off". IET renewable power generation, 5(3), pp. 234-244.

[6] Tedeschi, E., Carraro, M., Molinas, M., and Mattavelli, P., 2011. "Effect of control strategies and power take-off efficiency on the power capture from sea waves". Energy Conversion, IEEE Transactions on, 26(4), Dec, pp. 10881098.

[7] Hansen, R. H., Andersen, T. O., and Pedersen, H. C., 2011. "Model based design of efficient power take-off systems for wave energy converters". Proceedings of the 12th Scandinavian International Conference on Fluis Power, pp. 1-15.

[8] O'Sullivan, A. C., and Lightbody, G., 2017. "Co-design of a wave energy converter using constrained predictive control". Renewable Energy, 102, Part A, pp. 142 - 156.

[9] Hansen, R. H., Kramer, M. M., and Vidal, E., 2013. "Discrete displacement hydraulic power take-off system for the wavestar wave energy converter". Energies, 6(8), pp. 4001-4044.

[10] Kamizuru, Y., 2014. "Development of hydrostatic drive trains for wave energy converters". $\mathrm{PhD}$ thesis, RWTH Aachen University.

[11] Bailey, H., Robertson, B. R., and Buckham, B. J., 2016. "Wave-to-wire simulation of a floating oscillating water column wave energy converter". Ocean Engineering, 125, pp. 248-260.

[12] Forehand, D. I., Kiprakis, A. E., Nambiar, A. J., and Wallace, A. R., 2015. "A fully coupled wave-to-wire model of an array of wave energy converters". Sustainable Energy, IEEE Transactions on(99), pp. p 1-11.

[13] Babarit, A., Hals, J., Muliawan, M., Kurniawan, A., Moan, T., and Krokstad, J., 2012. "Numerical benchmarking study of a selection of wave energy converters". Renewable Energy, 41, pp. 44-63.

[14] Carballo, R., and Iglesias, G., 2012. "A methodology to de- 
termine the power performance of wave energy converters at a particular coastal location". Energy Conversion and Management, 61, pp. 8-18.

[15] de Andres, A. D., Guanche, R., Weber, J., and Costello, R., 2015. "Finding gaps on power production assessment on WECs: Wave definition analysis". Renewable Energy, 83, pp. 171-187.

[16] Rusu, E., and Onea, F., 2016. "Estimation of the wave energy conversion efficiency in the Atlantic Ocean close to the European islands". Renewable Energy, 85, pp. 687703.

[17] Rusu, L., and Onea, F., 2017. “The performance of some state-of-the-art wave energy converters in locations with the worldwide highest wave power". Renewable and Sustainable Energy Reviews, 75(November 2016), pp. 1348-1362.

[18] Mérigaud, A., and Ringwood, J. V., 2018. "Power production assessment for wave energy converters: Overcoming the perils of the power matrix". Proceedings of the Institution of Mechanical Engineers, Part M: Journal of Engineering for the Maritime Environment, 232(1), pp. 50-70.

[19] Robertson, B., Hiles, C., Luczko, E., and Buckham, B., 2016. "Quantifying wave power and wave energy converter array production potential". International Journal of Marine Energy, 14, pp. 143-160.

[20] Penalba, M., Touzón, I., Lopez-Mendia, J., and Nava, V., 2017. "A numerical study on the hydrodynamic impact of device slenderness and array size in wave energy farms in realistic wave climates". Ocean Engineering, 142, July, pp. 224-232.

[21] Ulazia, A., Penalba, M., Ibarra-Berastegui, G., Ringwood, J., and Saénz, J., 2018. "Wave energy trends over the bay of biscay and the consequences for wave energy converters". Energy, 25(2), pp. 44-45.

[22] Folley, M., 2016. Numerical Modelling of Wave Energy Converters: State-of-the-Art Techniques for Single Devices and Arrays. Academic Press.

[23] Cummins, W. E., 1962. The impulse response function and ship motions. Tech. rep., DTIC Document.

[24] Penalba, M., Kelly, T., and Ringwood, J. V., 2017. "Using NEMOH for modelling wave energy converters : A comparative study with WAMIT'. In 12th European Wave and Tidal Energy Conference, Cork, no. 631, pp. 1-10.

[25] Hasselmann, K., Barnett, T., Bouws, E., Carlson, H., Cartwright, D., Enke, K., Ewing, J., Gienapp, H., Hasselmann, D., Kruseman, P., Meerburg, A., Muller, P., Olbers, D., Richter, K., Sell, W., and Walden, H., 1973. Measurements of wind-wave growth and swell decay during the joint north sea wave project (jonswap). Tech. rep., Deutsches Hydrographisches Institut, Hamburg.

[26] Penalba, M., Mérigaud, A., Gilloteaux, J.-C., and Ringwood, J. V., 2017. "Influence of nonlinear froude-krylov forces on the performance of two wave energy points absor- bers". Journal of Ocean Engineering and Marine Energy, 3(3), Aug, pp. 209-220.

[27] Morison, J. R., O’Brien, M. P., Johnson, J. W., and Schaaf, S. A., 1950. "The forces exerted by surface waves on pliles". Petroleum Trans., AIME. Vol. 189, pp. 149-157.

[28] Penalba, M., Giorgi, G., and Ringwood, J. V., 2017. "Mathematical modelling of wave energy converters: A review of nonlinear approaches". Renewable and Sustainable Energy Reviews, 78, pp. 1188 - 1207.

[29] Giorgi, G., and Ringwood, J. V., 2016. "Computationally efficient nonlinear froude-krylov force calculations for heaving axisymmetric wave energy point absorbers". Journal of Ocean Engineering and Marine Energy, pp. 1-13.

[30] Giorgi, G., Penalba, M., and Ringwood, J. V., 2016. "Nonlinear hydrodynamic force relevance for different wave energy converter types". In Proceedings of the 3rd Asian Wave and Tidal Energy Conference, pp. 154-162.

[31] Penalba, M., Sell, N., Hillis, A., and Ringwood, J., 2017. "Validating a wave-to-wire model for a wave energy converter - Part I: The hydraulic transmission system". Energies, 10(7), p. 977.

[32] Penalba, M., Cortajarena, J.-A., and Ringwood, J. V., 2017. "Validating a wave-to-wire model for awave energy converter - Part II: The electrical system". Energies, 10(7), p. 1002.

[33] Jelali, M., and Kroll, A., 2012. Hydraulic servo-systems: modelling, identification and control. Springer Science \& Business Media.

[34] Schlösser, W., 1961. "Mathematical model for displacement pumps and motors". Hydraulic power transmission, pp. 252-257.

[35] Schlösser, W., 1968. "The overall efficiency of positivedisplacement pumps". In In BHRA Fluid Power Symposium, pp. 34-48.

[36] Krause, P. C., Wasynczuk, O., Sudhoff, S. D., and Pekarek, S., 2013. Analysis of Electric Machinery and Drive Systems, 3rd edition ed. IEEE Press Series on Power Engineering. Wiley-Blackwell.

[37] Irish marine institute. Available at http://www.marine.ie/Home/site-area/data-services/realtimeobservations/ wave-buoys.

[38] Genest, R., and Ringwood, J. V., 2016. "A critical comparison of model-predictive and pseudospectral control for wave energy devices". Journal of Ocean Engineering and Marine Energy, 2(4), pp. 485-499.

[39] Faedo, N., Olaya, S., and Ringwood, J. V., 2017. “Optimal control, mpc and mpc-like algorithms for wave energy systems: An overview". IFAC Journal of Systems and Control.

[40] Cathey, J. J., Cavin, R. K., and Ayoub, A., 1973. "Transient load model of an induction motor". IEEE Transactions on Power Apparatus and Systems(4), pp. 1399-1406. 